American Journal of Environmental Science 1 (2): 149-158, 2005

ISSN 1553-345X

$\odot$ Science Publications, 2005

\title{
Contribution of Advective and Non-advective Heat Fluxes to the Heat Budget of a Shallow Lagoon
}

\author{
Rodríguez-Rodríguez Miguel \\ Department of Environmental Sciences, Pablo de Olavide University, Seville Spain \\ Moreno-Ostos Enrique and De Vicente-Alvarez Manzaneda Inmaculada \\ Water Research Institute, University of Granada, Spain
}

\begin{abstract}
The heat budget in a shallow lagoon has been established from field measurements at a bihourly scale. Information on the main advective and non-advective heat fluxes were collected during year 2003 at Nueva lagoon (Almería, Southern Spain). Heat storage data was obtained from a thermistor chain located in the deepest part of the lagoon and meteorological information was acquired using an automatic meteorological station placed near the lagoon's shore. In addition, estimation of evaporation was inferred from climatic approaches. Inputs of heat energy were dominated by radiative fluxes, with received net radiation accounting on average for around $95 \%$ of the non-advective total gains and radiation losses accounting for around $70 \%$ of the non-advective total losses. Sensible heat transfer from/to the atmosphere constituted the second energy input (4\%) and output (20\%), although heat losses by evaporation were also significant. Conduction of heat into the sediments was a relatively constant form of energy loss but constitutes a minor contribution on the overall heat budget. Considerable variability was evident in nonadvective heat fluxes at different time scales, from diel to seasonal. In relation to advective heat fluxes, groundwater and irrigation surpluses added to the heat storage of Nueva lagoon, whereas heat advected via precipitation was negligible.
\end{abstract}

Key words: Energy budget, advective and non-advective fluxes, coastal lagoon, diel variations

\section{INTRODUCTION}

One of the major energy sinks of wetland ecosystems is latent heat flux, which is equivalent, in energy terms, to evaporation from a water surface. This term it is also one of the main components of the water balance in aquatic systems and, in fact, constitutes the main water sink in closed lakes. Consequently, an accurate estimation of evaporation rates will lead both to a validation of surface energy balance models and water budget studies.

Methods used to measure or model evaporation vary considerably, with significant implications for the accuracy of the results ${ }^{[1]}$. The majority of these techniques requires high-quality instrumentation and are most applicable to short-term studies rather than long-term monitoring. In addition, surface energy fluxes vary considerably in a daily scale, so short-term data are required to achieve accurate estimations. Consequently, these techniques have not been widely applied in wetland environments during a long period of time, as several months or even a complete year.

As part of an integrated EU-LIFE project on the conservation and restoration of Adra lagoons (Andalusia, Spain), a set of high temporal resolution measurements (air temperature, temperature of the water column, relative air humidity, wind speed and solar radiation) were taken to

establish the energy balance in Nueva lagoon during 2003. Latent heat flux data were calculated using the Penman approach in a daily scale from a nearby meteorological station in order to validate the model. Groundwater temperature was measured from a set of piezometers located around the whole perimeter of the lagoons. Energy budgets for coastal wetlands, may take into account the relationship between groundwater (coastal aquifer) and surface water (lagoon), as groundwater recharge could modify the energy inputs to the surface system ${ }^{[2]}$. Despite the importance of groundwater to the thermal regime of shallow lakes, there are very few studies on the fundamental heat fluxes that influence wetlands dominated by groundwater recharges. The present study reports a field investigation in which heat budgets have been quantified using detailed measurements (bihourly averages). Data were collected during a complete year in order to detect any seasonal contrast. The objectives of this study are (i) to evaluate two different climatic methods for evaporation estimates from a water surface, one of them integrated in an energy balance model (ii) to estimate energy interchange fluxes from a model using

\section{Corresponding Author: Rodríguez-Rodríguez Miguel, Carretera de Utrera Km 1, Sevilla 41013, Spain}

Tel: +00 34954349524 Fax: +00 34954419151 
micrometeorological data and (iii) to calculate the water budget in the lagoon, in order to estimate fluxes due to advection in the system.

\section{MATERIALS AND METHODS}

Study site: The study lake is situated in the Southwest of the province of Almería (Spain), on the Adra River basin $\left(746 \mathrm{~km}^{2}\right.$ of which the delta of the Adra River takes $22 \mathrm{~km}^{2}$ ) (Fig. 1). The Nueva lagoon (3.5 m maximum depth; 29 ha surface) forms part of the Adra Lagoons Natural Reserve, a wetland located in the easternmost part of the delta. The whole delta is nowadays occupied with intensive agriculture (greenhouses), so the lagoon bears a great environmental impact due to lixiviation of pesticides and fertilizers through permeable materials. Several irrigation canals distribute water from the Adra River and pumped from the Adra River Delta aquifer. Surplus of irrigation runs into the Albufera de Adra lagoons, making up a considerable fraction of the water budget ${ }^{[3]}$.

The lagoons are located over the Internal Zones of the Betic mountain range in the domain area of the Alpujárride Complex (Sierra de Gádor unit). These materials are basically Triassic phillites and quartzites over which lies a limestone-dolomite block ${ }^{[4]}$.

The area has an annual average temperature of $18^{\circ} \mathrm{C}$, being the minimum in January $\left(11^{\circ} \mathrm{C}\right)$ and the maximum in august $\left(26^{\circ} \mathrm{C}\right)$. Many hours of sunshine and the protection of the surrounding sierras are the main factors involved in the warm average temperatures, which are the highest of the province. The annual precipitation is very low, around $400 \mathrm{~mm}$ on average and presents a typical Mediterranean regime with most of the rainfall occurring in autumn $(102 \mathrm{~mm})$ and winter $(120 \mathrm{~mm})$.

Heat budget: Daily evaporation was calculated using the Penman approach, which combined energy-budget and mass-balance methods to estimate evaporation from freewater surfaces, as follows:

$$
\mathrm{E}=\mathrm{R}_{\mathrm{n}} \frac{\Delta}{\Delta+\gamma}+\mathrm{E}_{\mathrm{a}} \frac{\gamma}{\Delta+\gamma}
$$

Where $\mathrm{E}$ is the daily evaporation rate $\left(\mathrm{mm} \mathrm{day}^{-1}\right), \Delta$ the slope of the saturation vapour pressure curve at the air temperature, $\gamma$ the psychrometric constant and $E_{a}$ is the drying power of the air, given as a daily rate $\left(\mathrm{mm} \mathrm{day}^{-1}\right)$ by:

$\mathrm{E}_{\mathrm{a}}=f(\mathrm{u})\left(\mathrm{e}_{\mathrm{w}}-\mathrm{e}\right)$

Where $\left(e_{w}-e\right)$ is the saturation deficit, difference between the saturated $\left(\mathrm{e}_{\mathrm{w}}\right)$ and the actual (e) vapour pressure (mbars) and $\mathrm{f}(\mathrm{u})$, the Penman's function of wind $^{[5,1]}$. These data where acquired from Adra meteorological station (30S UG 500710.4066978, 42 m asl) in order to compare and validate evaporation results obtained by the heat budget methodology. Data from Adra station are public and accessible through a web-link ${ }^{[6]}$.

Heat budget was established by detailed monitoring of hydro-meteorological variables using in-lake equipment (a fixed buoy situated in the centre of the lagoon, to obtain water column temperatures from a chain of 10 submersed thermistors) and an adjacent to Nueva lagoon Squirrel MiniMet automatic station (Fig. 1).

The energy budget calculated for the lake, involve the vertical surface exchange that result from the portioning of incident solar (short wave) radiation (Qsa), long-wave radiation absorbed (Qla) and emitted (Qle), sensible heat flux, which is a convective energy flux in response to a temperature gradient (Qsh) and latent heat flux (Qec), which is a convective energy flux in response to a change of state among solid, liquid and gas phases. In the present heat budget, Qec is the energy gained by the lagoon through condensation (Qec $>0$ ) or loosed by evaporation $(\mathrm{Qec}<0)$. Conductive heat exchange with the stream bed (Qhb) was also calculated. Advective heat fluxes considered in the energy budget were heat fluxes due to precipitation (Qp), heat fluxes due to irrigation ditchs (Qi) and heat fluxes due to groundwater $(\mathrm{Qg})$. Heat fluxes resulting from biological and chemical reactions were neglected due to morphology of the lake and time scale under consideration. Total net heat exchange (Qn), can be expressed as:

$\mathrm{Qn}=\mathrm{Qsa}+\mathrm{Qla}-\mathrm{Qle} \pm \mathrm{Q} s h \pm \mathrm{Qec}+\mathrm{Qp}+\mathrm{Qi} \pm \mathrm{Qg}$

Incident solar short-wave radiation (Qsa) absorbed by the water surface is the region of the spectrum between 0.3 and $3 \mu \mathrm{m}$. The main factors affecting this variable are surface albedo and cloud cover, both reducing the theoretical total incident solar radiation. Bihourly data of incident short-wave radiation was directly measured using a radiometer.

Long-wave radiation absorbed by the lagoon (Qla) comes principally from water vapour, cloud droplets, carbon dioxide and ozone. The radiation is a function of the air temperature and was computed according to empirical relations.

Qla $=(1-\mathrm{A}) \sigma\left(\mathrm{T}_{\mathrm{a}}\right)^{4} \varepsilon_{0} f\left(\mathrm{C}^{\prime}\right)$

The above equation is the Stefan-Boltzmann expression modified by several environmental factors. Here $\mathrm{A}=$ albedo, $\mathrm{T}_{\mathrm{a}}=$ absolute air temperature $\left({ }^{\circ} \mathrm{K}\right), \sigma$ the Stefan-Boltzmann constant and $\varepsilon_{0}$ the atmospheric emissivity, a function of the water vapour pressure in 


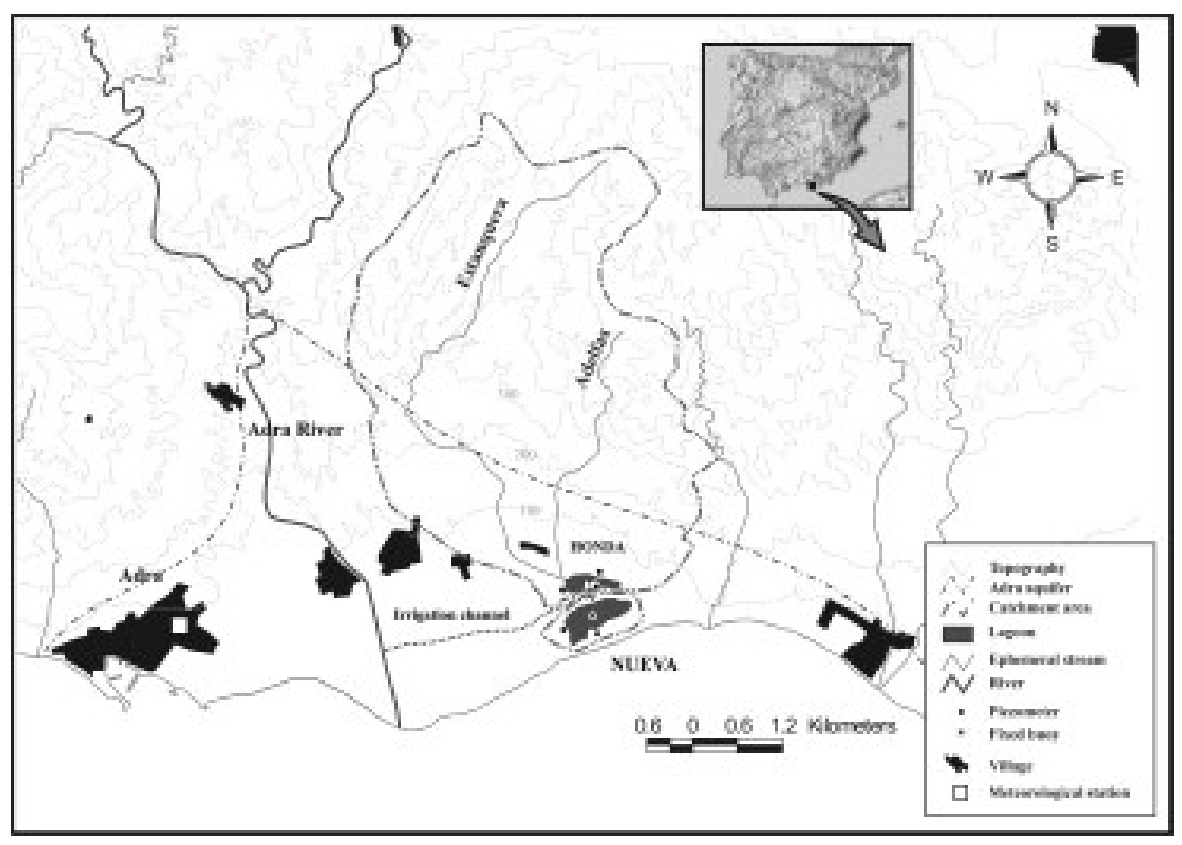

Fig. 1: Study site

the atmosphere $(\%)$ and air temperature, computed following Idso ${ }^{[7]}$.

Bihourly values of long wave radiation emitted from the lake (Qle) were computed taking into account that water radiates as a grey body rather than as a black one. Thus,

$\mathrm{Qle}=\sigma\left(\mathrm{T}_{\mathrm{w}}\right)^{4} \varepsilon_{\mathrm{w}}$

Where emissivity $(\varepsilon)=0.96$ and $\mathrm{T}_{\mathrm{w}}$ is the absolute surface water temperature determined at a depth of $0.5 \mathrm{~m}$. Therefore, this term can be considered as an approximation of the lake surface temperature and this was also used to calculate the surface saturation water vapour pressure.

Finally, net radiation $(\mathrm{Qr})$ can be obtained as follows:

$\mathrm{Qr}=\mathrm{Qsa}+\mathrm{Qla}-\mathrm{Qle}$

Energy used for evaporation/condensation, or latent heat flux, (Qec) is the result of heat budget itself as it measures the energy resulting from evaporation/ condensation processes. The sign indicates the energy transfer, being negative if evaporation predominates and vice versa. Empirical approximations ${ }^{8,9]}$ were used to compute this term of the heat budget:

$\mathrm{Qec}=-\mathrm{f}_{\mathrm{e}}\left(\mathrm{e}_{\mathrm{w}}-\mathrm{e}_{\mathrm{a}}\right)$

Here $f_{e}$ is an empirical transfer function ${ }^{[10]}$ based on the air and water temperatures and the wind speed $\left(\mathrm{u}_{12}\right) 12$ $\mathrm{m}$ above the ground $\left(\mathrm{ms}^{-1}\right)$; $\mathrm{f}_{\mathrm{e}}=4.8+1.92 \mathrm{u}_{12}+\left(\mathrm{T}_{\mathrm{w}}-\mathrm{T}_{\mathrm{a}}\right)$

$\mathrm{e}_{\mathrm{w}}$ and $\mathrm{e}_{\mathrm{a}}$ are the partial vapour pressure in the water and in the atmosphere, respectively and were calculated using Richards' equation ${ }^{[3]}$.

The sensible heat flux (Qsh) is the energy flux resulting from molecular and turbulent conduction when there is a movement of the fluid (i.e. wind stress). Again, empirical relations were used to compute this variable:

Qsh $=-0.63 f_{e}\left(T_{w}-T_{a}\right)$

Where, the constant 0.63 is Bowen's ratio $\left(\mathrm{mbar} \mathrm{K}^{-1}\right.$ ).

Conductive heat exchange $(\mathrm{Qhb})$ with the lagoon bed was calculated as:

$\mathrm{Qhb}=\mathrm{K} \mathrm{T}_{\mathrm{g}}$

where $\mathrm{K}=$ thermal conductivity of bed material $\left(\mathrm{J} \mathrm{m}^{-1} \mathrm{~s}^{-1}{ }^{\circ} \mathrm{C}^{-1}\right), \mathrm{T}_{\mathrm{g}}=$ temperature gradient in bed material $\left({ }^{\circ} \mathrm{Cm}^{-1}\right)$. Sensors were inserted at a depth of c. 5 and $30 \mathrm{~cm}$ below the lagoon surface in order to determine the temperature gradient in the bed material. Results were then multiplied by the area of the lagoon's bed and units were changed to $\mathrm{Wm}^{-2}$, as $1 \mathrm{cal} \mathrm{cm}^{-2}$ $\mathrm{h}^{-1}=4.1910^{-4} \mathrm{~J} \mathrm{~m}^{-2} \mathrm{~h}^{-1}=11.63 \mathrm{Wm}^{-2}$.

More detailed information ${ }^{[1]}$ about the aforementioned methodology is available in the literature. Advective fluxes were obtained at a monthly scale by 
means of the estimation of the lagoon's water budget, given as:

$$
\Delta V=P-E+S_{i}-S_{O}+G_{i}-G_{O}
$$

Where $G_{i}$ is groundwater inflow, $G_{0}$ is groundwater outflow, $\Delta \mathrm{V}$ is change in lagoon's water storage, $\mathrm{P}$ is precipitation, $\mathrm{E}$ is evaporation, $\mathrm{S}_{\mathrm{i}}$ is surface water inflow and $S_{o}$ is surface water outflow. As the lagoon is considered as terminal, $S_{0}$ cancels out. Surface water inflow has been periodically measured in the irrigation ditch flowing into the lagoon and daily evaporation and precipitation data were obtained from Adra weather station.

In order to obtain relative incidence of advective fluxes to the heat budget, change in storage of thermal energy in the water column was obtained. The total heat content (change in storage) of the water column ${ }^{[12]}$ was quantified following the equation:

$\mathrm{Q}_{\mathrm{t}}=\frac{1}{A_{0}} \sum_{z_{0}}^{z_{m}} t_{z} A_{z} h_{z}$

Where $Q_{t}=$ change in heat content of the lake in cal $\mathrm{cm}^{-2} \mathrm{~h}^{-1}, \mathrm{~A}_{0}=$ lagoon area $\left(\mathrm{cm}^{2}\right), \mathrm{z}_{0}=$ surface of the lagoon, $\mathrm{z}_{\mathrm{m}}=$ maximum depth, $\mathrm{t}_{\mathrm{z}}=$ average temperature in ${ }^{\circ} \mathrm{C}$ of a unit layer of water of thickness $\mathrm{h}_{\mathrm{z}}$ in $\mathrm{cm}$, with the midpoint at depth $\mathrm{z}$ and $\mathrm{A}_{\mathrm{z}}=$ the area at depth $\mathrm{z}$ in $\mathrm{cm}^{2}$. Volume in $\mathrm{cm}^{3}$ was then multiplied directly by temperature in ${ }^{\circ} \mathrm{C}$ to obtain caloric content. The hypsographic curve of Nueva lagoon was used to obtain $\mathrm{A}_{\mathrm{z}}$. Information on the temperature at different depths $\left(\mathrm{t}_{\mathrm{z}}\right)$ in the lake was obtained from a thermistors chain which encompassed 10 depths from $0.5 \mathrm{~m}$ to $2.5 \mathrm{~m}$, with a constant interval of $20 \mathrm{~cm}$ between the probes. The thermistor chain was attached to a fixed buoy in the deepest point of the lagoon and the bihourly temperature data (maximum error in the readings was $\pm 0.05^{\circ} \mathrm{C}$ ) were stored in a Squirrel Grant data logger.

There are many equations available for the estimation of these heat fluxes, especially for the Qsa, Qec and $\mathrm{Qsh}^{[13]}$; choosing another equation may easily result in a difference of $20-50 \mathrm{Wm}^{-2}$ in the heat flux estimate ${ }^{[14]}$. Nevertheless, the results provided using these techniques are in accordance with previous studies in other Spanish aquatic ecosystems ${ }^{[15,11]}$.

\section{RESULTS}

Air and water temperatures are the main variables that affect energy exchanges from water surface on an aquatic system. Plotting of average diel cycles for surface water in Nueva lagoon and air temperature in winter and summer (Fig. 2) reveals that water temperature has a modest diel variation compared with that of air temperature. Average daily range for surface water temperature was $0.59^{\circ} \mathrm{C}$ in the winter period and $1.82^{\circ} \mathrm{C}$ in the summer period. Daily ranges for air temperature in winter and summer were $10.16^{\circ} \mathrm{C}$ and $11.79^{\circ} \mathrm{C}$, respectively. From the obtained results, a relative insensitivity of water temperature to changes in air temperature is observed in the lake, probably due to the groundwater recharge from the detritic aquifer.


Fig. 2: Average diel cycles of air and water temperature $\left({ }^{\circ} \mathrm{C}\right)$ for the study site during the winter and the summer periods

A summary of the data recorded over the whole year, separated in seasons (Table 1) shows that the variation of surface water temperature in the lagoon was much less

\begin{tabular}{|c|c|c|c|c|c|c|c|c|}
\hline & \multicolumn{2}{|c|}{ Winter } & \multicolumn{2}{|l|}{ Spring } & \multicolumn{2}{|c|}{ Summer } & \multicolumn{2}{|c|}{ Autumm } \\
\hline & Air & Water & Air & Water & Air & Water & Air & Water \\
\hline Maximum & 23.95 & 16.85 & 33.00 & 26.45 & 42.34 & 32.25 & 38.15 & 30.38 \\
\hline Mean & 12.69 & 13.42 & 17.49 & 18.48 & 29.23 & 27.78 & 21.25 & 22.05 \\
\hline Minimum & 5.75 & 10.25 & 8.30 & 10.48 & 15.15 & 24.10 & 8.00 & 15.55 \\
\hline $\mathrm{n}$ & \multicolumn{2}{|c|}{639} & \multicolumn{2}{|c|}{1066} & \multicolumn{2}{|c|}{1103} & \multicolumn{2}{|c|}{1103} \\
\hline
\end{tabular}

than that of air temperature. Mean water temperature was slightly higher $\left(\mathrm{c} .0 .73^{\circ} \mathrm{C}\right)$ than mean air temperature in 
Am. J. Environ. Sci., 1 (2): 149-158, 2005

Table 2: Meteorological variables involved in the heat budget during year 2003

\begin{tabular}{lcrrrrr}
\hline Month & $\mathrm{Rh}(\%)$ & \multicolumn{1}{c}{$\sigma$} & $\mathrm{U} 2\left(\mathrm{~ms}^{-1}\right)$ & \multicolumn{1}{c}{$\sigma$} & $\mathrm{Qs}\left(\mathrm{Wm}^{-2}\right)$ & \multicolumn{1}{c}{$\sigma$} \\
\hline January-03 & 59.3 & 9.6 & 2.5 & 1.3 & 108.3 & 168.5 \\
February-03 & 64.8 & 9.4 & 1.8 & 0.9 & 113.5 & 183.3 \\
March-03 & 68.0 & 13.9 & 1.5 & 0.7 & 158.1 & 231.1 \\
April-03 & 68.9 & 6.3 & 2.2 & 1.0 & 236.3 & 304.9 \\
May-03 & 70.0 & 6.4 & 1.7 & 0.8 & 289.7 & 340.3 \\
June-03 & 71.8 & 7.7 & 1.5 & 0.5 & 296.9 & 334.5 \\
July-03 & 72.5 & 5.1 & 1.2 & 0.5 & 296.4 & 332.0 \\
August-03 & 69.1 & 6.6 & 1.2 & 0.5 & 254.4 & 302.3 \\
September-03 & 71.0 & 6.8 & 1.4 & 0.5 & 202.9 & 268.1 \\
October-03 & 72.0 & 7.9 & 1.5 & 0.6 & 128.3 & 197.9 \\
November-03 & 68.6 & 7.1 & 1.9 & 0.6 & 97.6 & 156.3 \\
December-03 & 63.7 & 8.5 & 2.1 & 0.8 & 92.9 & 150.9 \\
Year & 68.3 & 7.9 & 1.7 & 0.7 & 189.6 & 247.5 \\
Number of & \multicolumn{7}{c}{$150-372$} & & $150-372$ \\
data for each month average & & & & & \\
\hline \multicolumn{7}{c}{} \\
\hline
\end{tabular}

winter, spring and autumn, but nearly $1.5^{\circ} \mathrm{C}$ lower in summer.

Apart from water and air temperature, meteorological data involved in the heat budget can be observed in Table 2. Relative humidity was high during the whole year (c.70\% on average) due to the proximity of the lagoon to the sea shore, no more than $250 \mathrm{~m}$ and high temperatures. Wind velocity was higher in January, April and December $\left(>2 \mathrm{~ms}^{-1}\right.$ ) but didn't descend below $1 \mathrm{~ms}^{-1}$ during the rest of the year. Average typical deviation computed for wind speed was 0.7 .

High solar radiation during the whole year is a key factor with a great deal of influence in the heat budget in any ecosystem; Nueva lagoon received a c. $190 \mathrm{Wm}^{-2}$ average radiation during 2003, being higher in June and July and lower in November and December.

Monthly averages for non-advective heat fluxes obtained in Nueva lagoon during the study period are shown in Table 3 . In addition, Penman daily evaporation results obtained from Adra weather station are also shown. It can be observed that radiative fluxes, Qsa $\left(+161 \mathrm{Wm}^{-2}\right)$, Qla $\left(+270 \mathrm{Wm}^{-2}\right)$ and Qle $(-403$ $\mathrm{Wm}^{-2}$ ) are the most important components of the heat budget; the overall effect of non-advective radiative fluxes is to add heat energy to the lagoon, although this phenomenon is more pronounced in the summer. For the duration of four months of the year, radiation budget is negative.

Convection (Qec and Qsh) and conduction (Qhb) are, on an annual scale, major sinks of thermal energy of the system. The data shown in Table 3 depict that the net global balance of non-advective heat fluxes is negative, but change in thermal energy stored in the lagoon is not observed. Compensation of the energy balance is due to advective heat fluxes, mostly groundwater recharge and inflow from irrigation ditches, as will be discussed later on this study.

The Penman combination approach provides an annual evaporation rate of $1239.6 \mathrm{~mm}$ (Table 2), whereas the heat budget would lead to an annual evaporation rate of 1226.1. The energy balance and the Penman method yield mean annual evaporation rates that constitute a difference of $13.5 \mathrm{~mm}$, that is 1.08 and $1.10 \%$ of the annual evaporation values. Rigorous uncertainty calculations would be unrealistic because all methods include assumptions on empirical equations whose associated errors are difficult or impossible to estimate. However, the consistency of the results can be discussed through sensitivity analysis of the two methods to their respective input variables: measured data (air temperature, relative humidity, wind speed and short-wave radiation) and the Bowen ratio.

Analysis of the influences of individual input variables on evaporation estimated for both methods (by varying their value by $\pm 10 \%$ ) reflects that they are mainly sensitive to the short-wave radiation, which is the energy source of evaporation. The energy balance method is the most sensitive to this parameter. Air temperature is also a common variable to both methods. In the energy balance method it appears only through the calculation of longwave radiation and it does not significantly influence the evaporation rate. In the Penman method the sensitivity to temperature is larger. Uncertainties on wind speed data affect the Penman evaporation rate, but this variable has low influence. A $10 \%$ variation of the Bowen ratio, used in the energy balance method, only slightly changes the evaporation estimate. Assuming a 10\% error in all the input variables, the cumulative errors in the evaporation rates would range between 10 and $20 \%$, so both methods provide consistent inter-annual evaporation rates.

From the results obtained in the heat budget, evaporation/condensation heat fluxes have a net effect of removing energy from the lake during both the winter and the summer periods, although more strongly in the latter. Similar situation occurs with sensible heat. In any case, a small fraction of the overall heat budget is positive both for sensible heat and condensation.

The average absolute, percentage gain and losses and duration (fraction of the year) of non-advective heat energy in the study site are detailed in Table 4. Radiation was the major input and accounted for $>94 \%$ of the total non-advective energy gains. Condensation and bed conduction from the lagoon's floor were the minor inputs, both totalizing less than $0.5 \%$ of the total non-advective energy inputs. Nevertheless, some gain in heat was computed as a result of condensation as discussed earlier, c. $7 \%$ of the duration of the year. Significant amounts of heat energy were added to the lagoon by sensible transfer, especially on the summer period, although total contribution on the heat budget was less than $2 \%$. The average sensible heat gain was greater in both absolute and percentage terms for the summer period, when the cooling influence of groundwater flow was most marked and air temperature was higher than water temperature. 
Am. J. Environ. Sci., 1 (2): 149-158, 2005

Table 3: Monthly averages of non-advective heat fluxes and evaporation rates obtained from the energy balance and the Penman equation

\begin{tabular}{|c|c|c|c|c|c|c|c|c|}
\hline \multirow{3}{*}{$\frac{\text { Month }}{\text { January-03 }}$} & \multicolumn{2}{|c|}{ Evaporation rate $(\mathrm{mm})$} & \multirow[b]{2}{*}{ Qle $\left(\mathrm{Wm}^{-2}\right)$} & \multirow[b]{2}{*}{$\operatorname{Qr}\left(\mathrm{Wm}^{-2}\right)$} & \multirow[b]{2}{*}{$\mathrm{Qsh}\left(\mathrm{Wm}^{-2}\right)$} & \multirow[b]{2}{*}{$\mathrm{Qhb}\left(\mathrm{Wm}^{-2}\right)$} & \multirow{2}{*}{\multicolumn{2}{|c|}{ Energy balance (Qe Penman ) }} \\
\hline & Qsa $\left(\mathrm{Wm}^{-2}\right)$ & Qla $\left(\mathrm{Wm}^{-2}\right)$ & & & & & & \\
\hline & 92.4 & 245.7 & -357.8 & -6.6 & -2.5 & -1.6 & 74.2 & 67.9 \\
\hline February-03 & 96.5 & 247.4 & -359.4 & -5.2 & -4.1 & -1.7 & 46.5 & 59.0 \\
\hline March-03 & 134.4 & 258.7 & -377.6 & 5.2 & -6.2 & -2.0 & 58.9 & 80.7 \\
\hline April-03 & 200.8 & 263.4 & -395.0 & 23.1 & -22.7 & -1.8 & 99.2 & 109.9 \\
\hline May-03 & 246.2 & 277.3 & -420.7 & 34.3 & -30.5 & -4.2 & 131.3 & 140.1 \\
\hline June-03 & 252.3 & 293.4 & -443.9 & 34.0 & -24.8 & -4.8 & 131.0 & 158.7 \\
\hline July-03 & 251.9 & 294.8 & -450.9 & 32.0 & -35.1 & -2.5 & 159.4 & 160.9 \\
\hline August-03 & 216.2 & 299.7 & -454.3 & 20.5 & -25.7 & -2.2 & 154.4 & 153.5 \\
\hline September- 03 & 172.5 & 289.0 & -434.9 & 8.8 & -20.2 & -1.8 & 109.6 & 116.3 \\
\hline October-03 & 109.1 & 273.5 & -408.4 & -8.6 & -18.4 & -1.3 & 92.5 & 77.6 \\
\hline November-03 & 83.0 & 253.3 & -380.8 & -14.8 & -27.7 & -1.4 & 94.7 & 58.3 \\
\hline December-03 & 79.0 & 245.5 & -363.4 & -13.0 & -17.0 & -1.3 & 74.3 & 56.8 \\
\hline Year & 161.2 & 270.1 & -403.9 & 9.1 & -19.6 & -2.2 & 1226.1 & 1239.6 \\
\hline
\end{tabular}

Heat losses from the lagoon were dominated by radiative fluxes, as a consequence of the warm climate of this region and the high radiation, although sensible heat transfer from the water body to the overlying air was more than $20 \%$ of the total losses during the study period. Evaporative losses were constant throughout the year (93\% of the time of the year), enhanced by windy conditions. This component of the heat budget constitutes more than 5\% of the global heat budget (Table 4). Energy losses from the lagoon's floor through conduction was not a very significant form of non-advective output in the study site, although a quasi-constant $(99.5 \%$ of the time of the year) flux of c. $4.5 \mathrm{Wm}^{-2}$ was obtained. This situation is probably due to the covering of the floor of the lagoon by macrophyte vegetation.

Transfer of energy by mass transfer (advective fluxes) to the lagoon is produced mainly by direct rainfall and water inflows to the system, via surface (irrigation surplus) or groundwater recharge. The percentage contribution of rainfall, groundwater and ditch contribution to the heat storage of Nueva lagoon is listed in Table 5. Contribution of each component is presented for winter, spring, summer and autumn 2003 in order to analyze seasonal patterns. The stored energy evolution in the lake was obtained from bihourly data of water temperature from a thermistors chain and then multiplied by the volume of each horizontal layer to obtain total calorie content in the water column. A difference in the heat storage of c. $4500 \mathrm{cal} \mathrm{cm}^{-1}$ was observed between summer $\left(\mathrm{c} .6500 \mathrm{cal} \mathrm{cm}^{-1}\right)$ and winter $\left(\mathrm{c} .3000 \mathrm{cal} \mathrm{cm}^{-1}\right)$ in Nueva lagoon, being the minimum (2311 cal cm$~^{-1}$ ) registered at $10.00 \mathrm{~h}$ on 1 February and the maximum $\left(6854 \mathrm{cal} \mathrm{cm}^{-1}\right)$ registered at $18.00 \mathrm{~h}$ on 15 August 2003 . Average heat content in the lagoon was $4876 \mathrm{cal} \mathrm{cm}^{-1}$. In addition, no change in heat storage was observed from 1 st January 2003 to 31 December 2003.

The amount of heat added by rainfall falling onto the water surface was small, being zero in the summer due to null precipitation. On an annual scale, average heat contribution by rainfall was c. $2 \%$. Groundwater inflow contributes more significantly to the heat storage of the lagoon, this influence was more pronounced in the summer period (c. $8 \%$ of total energy content in lake), when hydraulic gradients were higher. In this situation, groundwater discharge from the Delta of Adra River aquifer to the Mediterranean sea must be extremely small in that sector of the aquifer and the lagoon may behave as a groundwater sink, this process induced by high evaporation rates (159 mm month ${ }^{-1}$ in August 2003). Heat added by irrigation surplus was small in winter, but relatively constant in spring, summer and autumn (c. 6\%) being a considerable source of heat energy to the study site.

In relation to the thermal response of the lake to the diel variations in meteorological conditions and the resulting energy budget, we have selected three defined thermal phases: pre-stratification (from January to June), stratification (from July to August) and poststratification/overturn (from September to December). Here, thermal stratification is defined as a temperature difference greater than $1.5^{\circ} \mathrm{C}$ between surface and deep waters ${ }^{[16]}$. Figure 3 shows daily variations in nonadvective energy fluxes, energy stored, water-column temperature, wind speed and precipitation. Five-day periods have been selected in order to examine daily changes in each of the three thermal phases established.

During the pre-stratification phase, rainfall episodes could lead to a decrease on the air temperature and, consequently, to a reduction on the temperature of the water column of more than $3^{\circ} \mathrm{C}$ during a $24-\mathrm{h}$ period, as can be observed in Fig. 3a. In addition, wind speed exhibited considerable diel variations, the highest wind speed value occurred in the interval from 12.00 to $14.00 \mathrm{~h}$ $\left(14 \mathrm{~ms}^{-1}\right)$. Heat flux due to net radiation shows a strong periodic variation, with maximum midday values ranging from nearly $0 \mathrm{Wm}^{-2}$ (15 March) to more than $550 \mathrm{Wm}^{-2}$ (20 March), affecting the changes in storage of thermal energy. Minimum night-time radiative fluxes remain fairly constant (c. $-130 \mathrm{Wm}^{-2}$ ) during the pre-stratification phase. In cloudy and windy periods the lake could lose thermal energy during the whole day (Fig. 3a, see 17 march). Diel cooling and heating effects of the upper layers of Nueva lagoon were observed during the stratification period (Fig. 3b). 
Am. J. Environ. Sci., 1 (2): 149-158, 2005
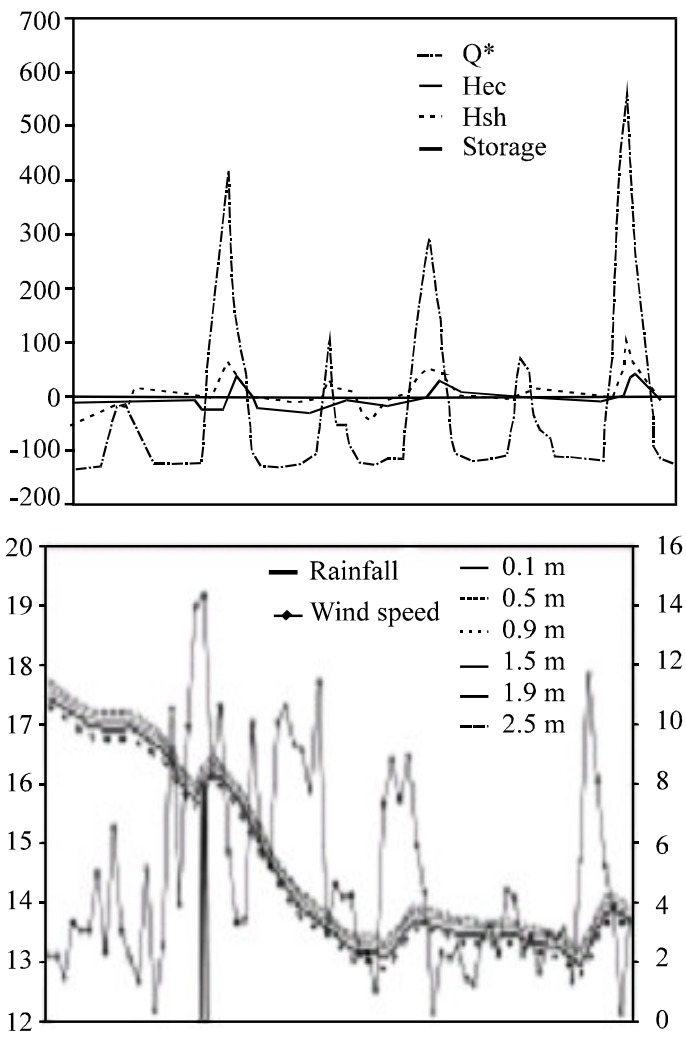

Fig. 3: Time series of energy balance data and energy stored $\left(\mathrm{Wm}^{-2}\right)$, water column temperature $\left({ }^{\circ} \mathrm{C}\right)$, left axis, wind speed $\left(\mathrm{ms}^{-1}\right)$ and precipitation (mm), right axis. From a) 15-20 March; b) 15-20 July and c) 15-20 October, 2003

As a consequence, a secondary shallow thermocline appears from 10.00 to $14.00 \mathrm{~h}$ almost every day, contributing to daily increments of the water column stability in the system. The average value of wind speed during stratification was $1.2 \mathrm{~ms}^{-1}$, but small-scale windy episodes (from 14.00 to $22.00 \mathrm{~h}, 15 \mathrm{July}$ ) with an average wind speed of c. $10 \mathrm{~ms}^{-1}$ lead to the gradual extension of the warmer surface water to greater depths and decreased the water column stability. From 16 July to 20 July, both gains and losses of thermal energy from net radiation were higher than that obtained in the pre-stratification period, +600 and $-180 \mathrm{Wm}^{-2}$, respectively. The consequence of the net energy exchange within the lake's surface resulted in changes in the heat energy storage which fits a sinusoidal curve. On a daily basis, the system was loosing energy to the atmosphere during night and early morning and gaining thermal energy during the sunlight period of the day.

Wind speed conditions during the post-stratification period (September to December 2003) varied from those measured during the stratification period. Average wind-speed was c. $2.5 \mathrm{~ms}^{-1}$, with maximum values rising
Table 4: Average absolute, percentage gain and losses and fraction of the year for non-advective heat fluxes during the study period

\begin{tabular}{|c|c|c|c|c|}
\hline $\begin{array}{l}\text { Component } \\
\text { Gains }\end{array}$ & $\begin{array}{l}\text { Flux } \\
\left(\mathrm{W} \mathrm{m}^{-2}\right)\end{array}$ & $\begin{array}{l}\text { Component } \\
(\%)\end{array}$ & $\begin{array}{l}\text { Fraction year } \\
(\%)\end{array}$ & Percentage \\
\hline Radiation & 302.79 & 94.76 & 51.25 & 48.57 \\
\hline Condensation & 0.92 & 0.29 & 6.86 & 0.02 \\
\hline Sensible heat & 15.26 & 4.78 & 34.64 & 1.65 \\
\hline Bed conduction & 0.56 & 0.18 & 0.57 & 0.00 \\
\hline Total & 319.53 & 100.00 & 93.32 & 50.24 \\
\hline \multicolumn{5}{|l|}{ Losses } \\
\hline Radiation & 130.00 & 71.06 & 48.75 & 34.64 \\
\hline Evaporation & 9.84 & 5.38 & 93.17 & 5.01 \\
\hline Sensible heat & 38.51 & 21.05 & 65.36 & 13.76 \\
\hline Bed conduction & 4.60 & 2.51 & 99.42 & 2.50 \\
\hline 182.95 & 100.00 & 306.69 & 55.91 & \\
\hline
\end{tabular}

Table 5: Average heat content of the lagoon and percentage contribution of advective heat fluxes to the heat budget in winter, spring, summer and autumn, 2003

\begin{tabular}{lcccc}
\hline Seasons & $\begin{array}{l}\text { Total calories } \\
\text { in lake }\left(\mathrm{cal} \mathrm{cm}^{2}\right)\end{array}$ & $\begin{array}{l}\text { Groundwater } \\
\text { contribution }\end{array}$ & $\begin{array}{l}\text { Rainfall } \\
\text { contribution }\end{array}$ & $\begin{array}{l}\text { Ditch } \\
\text { contribution }\end{array}$ \\
\hline Winter & 2830 & 1.43 & 3.65 & 2.32 \\
Spring & 4467 & 6.28 & 1.90 & 6.91 \\
Summer & 6468 & 5.23 & 0.00 & 6.79 \\
Autumm & 4959 & 8.82 & 4.33 & 6.51 \\
\hline
\end{tabular}

episodes is the source of colder water to the system that cools the water column. Energy storage reflects diel variations, but also an annual pattern, similar to that of net radiation absorbed or emitted by the lagoon, although with a delay of two months above $10 \mathrm{~ms}^{-1}(14.00 \mathrm{~h}$ on 18 and 19 October). The mixing effect of the wind on the lagoon is evident from the data obtained, so wind speed is the main factor involved in mixing processes in water surfaces. Heat gains from net radiation were also appreciably lower, maximum midday values ranging from 480 to $200 \mathrm{Wm}^{-2}$.

Diel evolution of water column temperature during this phase was very homogeneous and the differences between the temperature of surface and bottom water was not higher than $1.5^{\circ} \mathrm{C}$, so the water column can be considered as mixed. Average diel variation of non-advective heat fluxes in winter, spring, summer and autumn are depicted in Fig. 4. The net radiation changed from negative to positive values at c. $6.30 \mathrm{~h}$ in summer, whereas this change occurs at c. $9.30 \mathrm{~h}$ in winter. Change of net radiation from positive to negative values occurs at c. $18.00 \mathrm{~h}$ in summer and at c. $17.00 \mathrm{~h}$ in winter. Evaporative heat fluxes also show a diel cycle, at least in spring and summer, with maximum losses in the middle of the day. Conditions that promoted heat gain by condensation during short periods in the early morning and evening are not represented in Fig. 4, although they were occasionally detected within the study period. Such processes were not continuous in any season, so averaged values did not reproduce the situation in a seasonal scale. The diel changes of sensible heat flux have a similar pattern of values rising to a peak in the middle of the day, but there are differences within the different seasons. Heat gain through the air was greater in winter and took place 
Am. J. Environ. Sci., 1 (2): 149-158, 2005
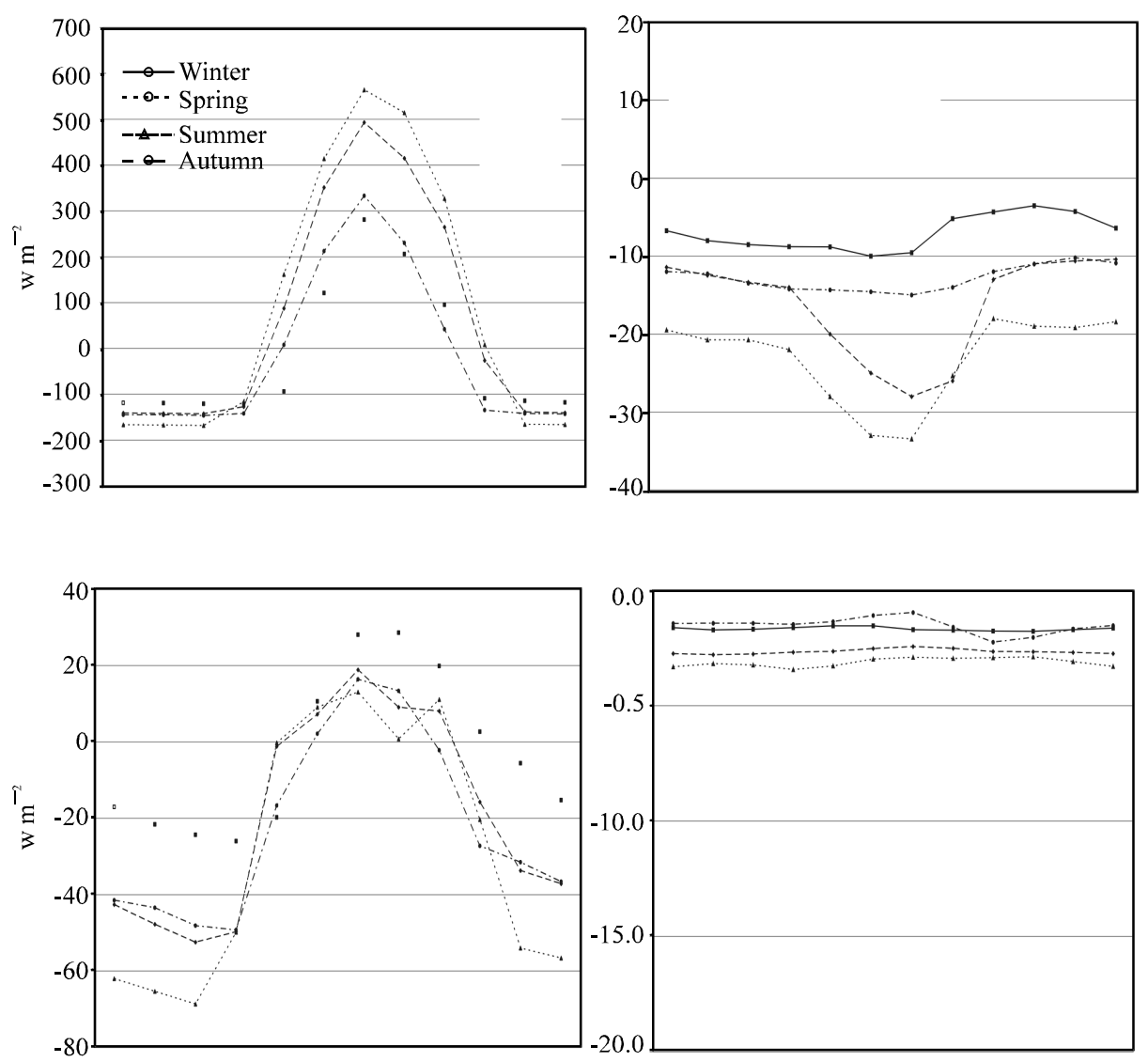

Fig. 4: Average diel variation of non-advective heat fluxes in winter, spring, summer and autumn, 2003, in Nueva lagoon

for all the diel cycle, except for the period between c. 20.00 and $8.00 \mathrm{~h}$. The seasonal diel variation of bed conduction ranged from -1 to $-3.5 \mathrm{Wm}^{-2}$ during the study period in Nueva lagoon. The variation in the course of 24$\mathrm{h}$ periods was not very strong, with constant losses throughout the day.

The overall energy balance in $\mathrm{Wm}^{-2}$ and energy storage evolution in Nueva lagoon $\left(\mathrm{cal} \mathrm{cm}^{-1}\right)$ for the study period is shown in Fig. 5. Drastic reductions in energy stored in the lagoon are related to rainfall episodes. Groundwater recharge associated with rainfall

\section{DISCUSSION AND CONCLUSION}

Annual water temperature in The Nueva lagoon exhibit a typical pattern for many coastal shallow lakes in the Mediterranean area $^{[17]}$. In addition, groundwater recharge to the lagoon has also been reported ${ }^{[18,3]}$ and constitutes a relatively considerable part both to the water and heat budgets. Published studies on heat budgets using detailed measurements with such a high temporal resolution are scarce and only confined for 24-h periods ${ }^{[16]}$. However, there are some literature available based on seasonal observations ${ }^{[14]}$ or about heat budgets made at a high temporal resolution in groundwater dominated rivers with continuous measurements during several days in winter and summer seasons ${ }^{[2]}$. The scarceness of published studies about heat budgets in wetlands is not observed in oceanic research. A recent study about the depth of formation of tropical thermoclines and its relation with the ocean heat budget stresses out the relevance of the timescale involved in the process $^{[19]}$. In Spain, an investigation by the authors on a high mountain lake (La Caldera, Sierra Nevada), where groundwater is a minor component of the water budget, revealed that short-wave radiation, long-wave radiation absorbed, long-wave radiation emitted, evaporation/condensation and sensible heat fluxes contributed on average 40,34, 33.5, 36 and $28 \%$ respectively to non-advective heat budget. The measuring period (74 days) takes a complete ice-free episode ${ }^{[11]}$.

Consideration of the data collected at two hour intervals reveals that the non-advective fluxes affecting the study site had a wide range of variation within the study period. Many of the main heat fluxes have a systematic diel 
fluctuation, whereas only heat gain due to radiation has also an annual fluctuation with a summer maximum. Besides, net radiation is a source of energy during the daylight hours, but is


Fig. 5: Overall energy balance $\left(\mathrm{Wm}^{-2}\right)$ and energy storage $\left(\mathrm{cal} \mathrm{cm}^{-2}\right)$ for the study perio

responsible for heat loss during the night-time when shortwave inputs from the sun ceases and back radiation of long-wave energy from the water surface dominates.

Heat flux due to evaporation also shows a diel cycle with maximum looses in the midday and early afternoon. Heat loss due to evaporation is reduced at nigh time. The diel changes of sensible heat flux are different within different seasons, but also exhibited a similar pattern, with values rising to a peak in the middle of the day. Changes in heat fluxes through bed conduction show little variations in a daily scale. This is a minor component of the of the heat budget as the lagoon floor is totally covered with submersed vegetation and this can be a factor that reduce bed conduction.

In terms of advective fluxes, the minor role of precipitation confirmed results gathered in water courses $^{[2]}$. Advection due to groundwater and irrigation surplus was a more constant and more significant source of heat in Nueva lagoon. No loss of groundwater to the Mediterranean Sea was recorded in the lagoon; this situation confirmed the result obtained in previous studies about the water budget in

this system ${ }^{[18]}$. Although groundwater contributes heat to the lagoon in both winter and summer, temperature differences between inflows and the lagoon water column mean that this input has a warming effect in winter but a cooling one in summer. Diel energy fluxes from and to the lake determine the thermal/density stratification, which is the major controlling factor in the plankton dynamics. The proper knowledge of the physical processes occurring in the aquatic ecosystem and its biological coupling is relevant to properly understand the ecosystem structure and dynamics. In this sense, the study of temporal scales governing different physical processes is of vital importance. As the heat exchange from the water surface to the atmosphere is both positive and negative during a 24-h period, this kind of environmental modeling has to be applied with at least bihourly data.

The present study has revealed considerable fluctuations in heat energy between and within days and the influence of groundwater recharge on the heat budget in Nueva lagoon during year 2003, although there is a need for further and longer-term research involving biological variables on Nueva lagoon and other aquatic ecosystems. In this sense, future research directions take account on the study of migrating patterns in phytoplankton and zooplankton communities in Nueva lagoon with a bihourly scale in order to detect the influence of physical limnology in biological dynamics.

\section{ACKNOWLEDGEMENTS}

We gratefully thank Professor Dr. J. Armengol from the University of Barcelona for collaboration in the development of the thermal balance methodology applied to Nueva lagoon. We also thank Dr. M. Paracuellos from the Andalusia Department of Environment for field assistance in the collection of micro-meteorological data. The investigation was part of a EC-LIFE Project of Environmental Conservation in the Albuferas of Adra (Contract LIFE 93/UK/3167).

\section{REFERENCES}

1. Vallet-Coulomb, C., D. Legesse, F. Gasse, Y. Travi and T. Chernet, 2001. Lake evaporation estimates in tropical Africa (Lake Ziway, Ethiopia). J. Hydrol., 245: 1-18. 
2. Webb, B.W. and Y. Zhang, 1999. Water temperatures and heat budgets in Dorset chalk water courses. Hydrol. Proccess, 13: 309-321.

3. Rodríguez-Rodríguez, M., 2002. Limnological and hydrogeological contribution to the environmental characterization of wetlands from Eastern Andalusia. Ph.D Thesis. University of Granada.

4. Aldaya, F., 1983. Geologic Map of Spain (Sheet 1057: Adra). IGME, Madrid.

5. Brutsaert, W. and H. Stricker, 1979. An advectionaridity approach to estimate actual regional evapotranspiration. Water Resour. Res., 15: 443-450.

6. www.juntadeandalucia.es. Agroclimatic Stations Net. Adra Station.

7. Idso, S.B., 1981. A set of equations for full spectrum and 8- to $14 \mu \mathrm{m}$ and 10.5 - to $12.5-\mu \mathrm{m}$ thermal radiation from cloudless skies. Water Resour. Res., 17: 295-304.

8. Colomer, J., E. Roget and X. Casamitjana, 1996. Daytime heat balance for estimating non-radiative fluxes of Lake Banyoles, Spain. Hydrol. Process, 10: 721-726.

9. Armengol, J., M. Comerma, J.C. García, M. Romero, J.J. Rodríguez and A. Vidal, 2000. Contribució al coneixement de l'ecologia acuática de l'embassament de Sau. Evolució de l'embassament al 1999. Quaderns Aigües Ter LLobregat, 3: 1-97.

10. Colomer, J. and X. Casamitjana, 1993. A model to calculate surface energy fluxes from routine meteorological data. Application to Lake Banyoles. Proceedings of the International Association of Theoretical and Applied Limnol., 25: 88-90.
11. Rodríguez-Rodríguez, M., E. Moreno-Ostos, I. De Vicente, L. Cruz-Pizarro and S. L. Rodrigues, 2004. Thermal structure and energy budget in a small high mountain lake: La Caldera, Sierra Nevada, Spain. NZ. J. Mar. Freshwat. Res., 38: 879-894.

12. Wetzel, R.G. and G.E. Likens, 1991. Limnological Analyses, second ed. Springer-Verlag, New York.

13. Henderson-Sellers, B., 1986. Calculating the surface energy balance for lake and reservoir modelling: A review. Rev. Geoph, 24: 625-649.

14. Schmid, M., A. Lorke, A. Wüest, M. Halbwachs and G. Tanyileke, 2003. Development and sensitivity analysis of a model for assessing stratification and safety of Lake Nyos during artificial degassing. Ocean Dynam, 53: 288-301.

15. Catalán, J., 1988. Physical properties of the environment relevant to the pelagic ecosystem of a deep high-mountain lake (Estany Redó, Central Pyrenees). Oecol. Aquat, 9: 89-123.

16. Frempong, E., 1983. Diel aspects of the thermal structure and energy budget in a small English lake. Freshwat. Biol., 13: 89-102.

17. Cruz-San Julián, J.J. and J. Benavente, 1996. Wetlands: a multiapproach perspective. Hydrological and Ecological Studies applied to Wetlands Management in Semiarid Climate. University of Granada.

18. Hermans, A., 1999. Water budget on the Albuferas of Adra. Water Research Institute. University of Granada.

19. Boccaletti, G., 2005. Timescales and dynamics of the formation of a thermocline. Dynam. Atmosph. Ocean, 39: 21-40. 